\title{
An analytical dynamic model of heat transfer from the heating body to the heated room
}

\author{
Jana Mižáková ${ }^{1}$ and Ján Pitel $^{1, *}$ \\ ${ }^{1}$ Technical University of Košice, Faculty of Manufacturing Technologies with a seat in Prešov, Bayerova 1, 08001 Prešov, Slovakia
}

\begin{abstract}
On the base of mathematical description of thermal balance the dynamic model of the hot-water heating body (radiator) was designed. The radiator is mathematically described as a heat transfer system between heating water and warmed-up air layer. Similarly, the dynamic model of heat transfer through the wall from the heated space to the outdoor environment was design. Both models were interconnected into dynamic model of heat transfer from the heating body to the heated room and they will be implemented into simulation model of the heating system in Matlab/Simulink environment.
\end{abstract}

\section{Hot-water heating body}

An analytic identification method based on mathematical description of a heat exchanger was chosen for design of the hot-water heating body dynamic model [1].

A hot-water heating body can be described as a heat transfer system between heating water and warmed-up air layer [2]. Heating water circulates inside radiator and delivers a heat through surface layer. External side of radiator is surrounded by air layer, which is warmed-up and heated air naturally flows up due to difference of specific weight [3]. It was considered ideal mixing of the heating water in internal space of the radiator and ideal air mixing in boundary layer of the radiator.

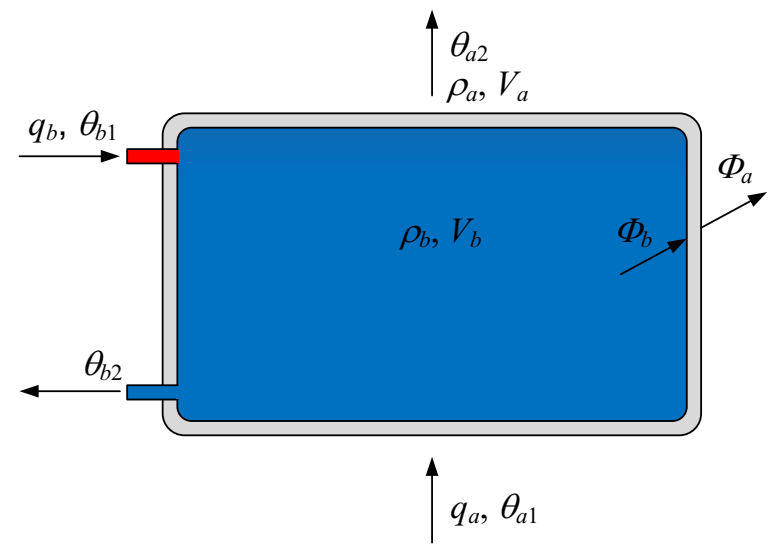

Fig. 1. Heat transfer in the heating body.

The heating water with mass flow $q_{b}$ and temperature $\theta_{b 1}$ inputs into radiator (Fig. 1). At every time point there is the volume of heating water $V_{b}$ with density $\rho_{b}$ in internal space of radiator. This water delivers a heat through surface layer of the radiator with plane $A_{r}$ which is surrounded by air layer. Temperature of the return heating water from radiator is $\theta_{b 2}$. The air flow rate is $q_{a}$, volume of air in boundary layer of the radiator is $V_{a}$, its input temperature to the radiator surface is $\theta_{a 1}$ and its output temperature after heating is $\theta_{a 2}$. Exchanged heat flow from heating water to the radiator wall is $\Phi_{b}$ and from the radiator wall to room space is $\Phi_{a}[4,5]$.

\subsection{Mathematical description of heat transfer in the heating body}

Generally, for dynamic balance describing of heat energy increasing or decreasing in system it is valid, that difference of input and output heat flows is equal to the time variation of the accumulated energy in a system [6]. Then the heat accumulation equation is valid for air heating in the boundary layer of the radiator:

$$
\Phi_{a}-q_{a} \cdot c_{a} \cdot\left(\theta_{a 2}-\theta_{a 1}\right)=\rho_{a} \cdot V_{a} \cdot c_{a} \cdot \frac{\mathrm{d} \theta_{a 2}}{\mathrm{~d} t}
$$

where $\Phi_{a}$ is heat flow from the radiator wall to the surrounding [W], $q_{a}$ is air flow in the boundary layer of the radiator $\left[\mathrm{kg} \cdot \mathrm{s}^{-1}\right], c_{a}$ is specific heat capacity (specific heat) of air $\left[\mathrm{J} \cdot \mathrm{kg}^{-1} \cdot \mathrm{K}^{-1}\right], \theta_{a 1}$ is input air temperature $[\mathrm{K}]$, $\theta_{a 2}$ is output air temperature $[\mathrm{K}], \rho_{a}$ is air density $\left[\mathrm{kg} \cdot \mathrm{m}^{-3}\right]$ and $V_{a}$ is air volume in the boundary layer of the radiator $\left[\mathrm{m}^{3}\right]$.

For heat exchanging from the heating water to the radiator wall this heat accumulation equation is valid:

$$
q_{b} \cdot c_{b} \cdot\left(\theta_{b 1}-\theta_{b 2}\right)-\Phi_{b}=\rho_{b} \cdot V_{b} \cdot c_{b} \cdot \frac{\mathrm{d} \theta_{b 2}}{\mathrm{~d} t}
$$

where $\Phi_{b}$ is heat flow from the heating water to the radiator wall [W], $q_{b}$ is mass flow rate of the heating water $\left[\mathrm{kg} \cdot \mathrm{s}^{-1}\right], c_{b}$ is specific heat capacity (specific heat) of water $\left[\mathrm{J} \cdot \mathrm{kg}^{-1} \cdot \mathrm{K}^{-1}\right], \theta_{b 1}$ is input water temperature into the radiator $[\mathrm{K}], \theta_{b 2}$ is temperature of the return heating

Corresponding author: jan.pitel@tuke.sk 
water from the radiator $[\mathrm{K}], \rho_{b}$ is water density $\left[\mathrm{kg} \cdot \mathrm{m}^{-3}\right]$ and $V_{b}$ is volume of water in the radiator $\left[\mathrm{m}^{3}\right]$.

It is necessary for design of automatic control to know the dynamic dependence of the control deviation according to changes of variables which have effect on the deviation [7-10]. For that reason, we express dependent variables in equations (1) and (2) by their values in initial steady-state and their increments. Next, to simplify computation, we express each of dependences in non-dimensional form as relative changes of variables and we get system of differential equations describing the radiator:

$$
\begin{gathered}
x_{\Phi a}-x_{\theta a 2}+x_{\theta a 1}-x_{q a}=\tau_{m a} \cdot \frac{\mathrm{d} x_{\theta a 2}}{\mathrm{~d} t} \\
-x_{\theta b 2}+x_{\theta b 1}+x_{q b}-x_{\Phi b}=\tau_{m a} \cdot \frac{\mathrm{d} x_{\theta b 2}}{\mathrm{~d} t}
\end{gathered}
$$

where $\tau_{m a}=\frac{\rho_{a} \cdot V_{a}}{q_{a 0}}$ and $\tau_{m b}=\frac{\rho_{b} \cdot V_{b}}{q_{b 0}}$ are time constants.

\subsection{Dynamic model of the hot-water heating body}

After Laplace transform of differential equations (3) and (4) and other mathematical operations it is valid for relative change of air output temperature:

$$
\begin{aligned}
& X_{\theta a 2}(s)=\frac{1}{\tau_{m a} \cdot s+1}\left[X_{\Phi a}(s)+X_{\theta a 1}(s)-X_{q a}(s)\right]= \\
& =G_{a}(s) \cdot\left[X_{\Phi a}(s)+X_{\theta a 1}(s)-X_{q a}(s)\right] \\
& X_{\theta b 2}(s)=\frac{1}{\tau_{m b} \cdot s+1}\left[-X_{\Phi b}(s)+X_{\theta b 1}(s)+X_{q b}(s)\right]= \\
& =G_{b}(s) \cdot\left[-X_{\Phi b}(s)+X_{\theta b 1}(s)+X_{q b}(s)\right]
\end{aligned}
$$

where $\tau_{m a}=\frac{\rho_{a} \cdot V_{a}}{q_{a 0}}$ and $\tau_{m b}=\frac{\rho_{b} \cdot V_{b}}{q_{b 0}}$ are time constants.

To make mathematical description of dynamic characteristics of the radiator complete, it is necessary to supplement equation (5) and (6) with relations for relative changes of heat flows $x_{\Phi a}$ and $x_{\Phi b}$. If heat transfer coefficients $h_{a}$ and $h_{b}$ are constant in unsteadystates, relative variations of heat flows are dependent only on temperature changes of the heating water and air. Generally, we can express it as:

$$
\begin{aligned}
& X_{\Phi a}(s)=W_{a b}(s) \cdot X_{\theta b 2}(s)-W_{a a}(s) \cdot X_{\theta a 2}(s) \\
& X_{\Phi b}(s)=-W_{b a}(s) \cdot X_{\theta a 2}(s)+W_{b b}(s) \cdot X_{\theta b 2}(s)
\end{aligned}
$$

Transfer functions in relations (7) and (8) are [2]:

$$
W_{a b}(s)=\frac{k_{b}}{1+\tau_{r} \cdot s} \quad W_{a a}(s)=k_{a} \cdot \frac{1+\tau_{b} \cdot s}{1+\tau_{r} \cdot s}
$$

gains $k_{b}, k_{a}$ :

$$
\begin{aligned}
& k_{b}=\frac{A_{r}}{q_{b 0} \cdot c_{b}} \cdot \frac{1}{\frac{1}{h_{a}}+\frac{1}{h_{b}}+\frac{d_{r}}{\lambda_{r}}} \\
& k_{a}=\frac{A_{r}}{q_{a 0} \cdot c_{a}} \cdot \frac{1}{\frac{1}{h_{a}}+\frac{1}{h_{b}}+\frac{d_{r}}{\lambda_{r}}}
\end{aligned}
$$

and time constants $\tau_{b}, \tau_{r}$ :

$$
\begin{gathered}
\tau_{b}=\rho_{r} \cdot c_{r} \cdot d_{r} \cdot\left(\frac{1}{h_{b}}+\frac{d_{r}}{2 \lambda_{r}}\right) \\
\tau_{r}=\rho_{r} \cdot c_{r} \cdot d_{r} \cdot \frac{1+\frac{\left(h_{a}+h_{b}\right) \cdot d_{r}}{2 \lambda_{r}}+\frac{h_{a} \cdot h_{b} \cdot d_{r}}{6 \lambda_{r}^{2}}}{h_{a}+h_{b}+\frac{h_{a} \cdot h_{b} \cdot d_{r}}{\lambda_{r}}}
\end{gathered}
$$

where other variables not mentioned above are: $A_{r}$ is plane of the radiator surface $\left[\mathrm{m}^{2}\right], h_{a}$ is heat transfer coefficient between radiator surface and air $\left[\mathrm{W} \cdot \mathrm{m}^{-2} \cdot \mathrm{K}^{-1}\right]$, $h_{b}$ is heat transfer coefficient between heating water and radiator body $\left[\mathrm{W} \cdot \mathrm{m}^{-2} \cdot \mathrm{K}^{-1}\right], d_{r}$ is thickness of the radiator wall $[\mathrm{m}], \lambda_{r}$ is heat conductivity coefficient of the radiator body material $\left[\mathrm{W} \cdot \mathrm{m}^{-1} \cdot \mathrm{K}^{-1}\right], \rho_{r}$ is specific weight of the radiator body material $\left[\mathrm{kg} \cdot \mathrm{m}^{-3}\right]$ and $c_{r}$ is specific heat capacity (specific capacity) of the radiator body material $\left[\mathrm{J} \cdot \mathrm{kg}^{-1} \cdot \mathrm{K}^{-1}\right][11,12]$.

Transfer functions $W_{b a}(s)$ and $W_{b b}(s)$ we get by reciprocity of indexes ,a" and ,b“ in terms (9).

Based on the terms (5) till (9) for non-dimensional variables the block diagram of dynamic model of the hot-water heating body was designed (Fig. 2).

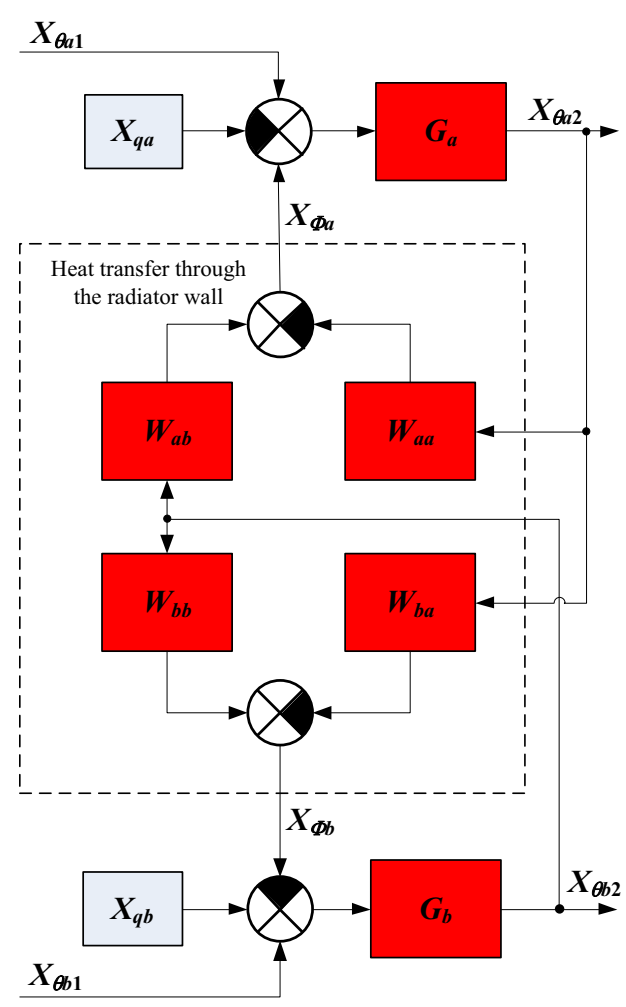

Fig. 2. Block diagram of dynamic model of the hot-water heating body. 
Input variables into model are non-dimensional variables or constants: input temperature of air $X_{\theta a 1}$, air flow rate $X_{q a}$, temperature of the input heating water into radiator $X_{\theta b 1}$ and mass flow rate of the heating water $X_{q b}$. Output variables from model are non-dimensional variables: output temperature of air after heating by the radiator surface $X_{\theta a 2}$ and temperature of the return heating water from the radiator $X_{\theta b 2}$.

\section{Heat transfer through the wall}

For design of the dynamic model of heat transfer through the wall we have considered a plane wall, where the wall has been considered as continuum with continuously distributed thermal resistance and capacity $[13,14]$. We have chosen elementary layer with following parameters (Fig. 3): thickness of the plane wall $\mathrm{d} w$ [m], layer thickness in the plane wall $\mathrm{d} y[\mathrm{~m}]$, distance of layer from the heated surface $y[\mathrm{~m}]$. The heat flow $\Phi_{1}[\mathrm{~W}]$ is supplied into heated wall surface which temperature is $\theta_{w 1}[\mathrm{~K}]$, the heat flow $\Phi_{2}[\mathrm{~W}]$ is taken away from the refrigerated wall surface which temperature is $\Phi_{2}[\mathrm{~W}]$. The heat flow $\Phi$ inputs into the unit surface of layer $\mathrm{d} y$, and the heat flow $\Phi+\mathrm{d} \Phi$ outputs from it. Temperature of the elementary layer is $\theta_{w}[\mathrm{~K}]$.

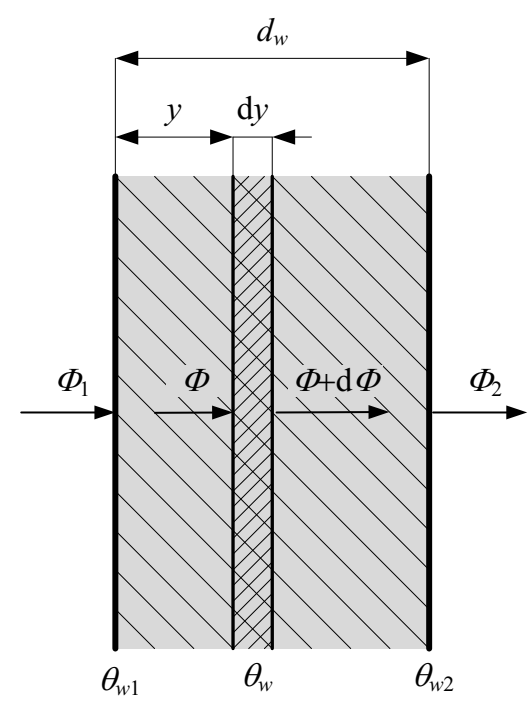

Fig. 3. Heat transfer through the plane wall.

\subsection{Mathematical description of heat transfer through the wall}

The heat energy does not originate either does not lose in considered elementary layer of the wall. Then difference of the input heat and output heat in the layer has to be equal to the time variation of the energy in the layer [15].

Let's $c$ is specific heat capacity (specific heat) and $\rho$ is volume weight of the wall material, then:

$$
\Phi-(\Phi+\mathrm{d} \Phi)=\frac{\partial}{\partial t}\left(c \cdot \rho \cdot \theta_{w} \cdot \mathrm{d} y\right)
$$

Considering that heat flow $\mathrm{d} \Phi$ is:

$$
\mathrm{d} \Phi=\frac{\partial \Phi}{\partial y} \mathrm{~d} y
$$

If specific heat capacity $c$ and volume weight $\rho$ of the used wall material are constant, then [16]:

$$
-\frac{\partial \Phi}{\partial y}=c \cdot \rho \cdot \frac{\partial \theta_{w}}{\partial t}
$$

According to Fourier's law the heat flow is directly proportional to the temperature gradient:

$$
\Phi=-\lambda \frac{\partial \theta_{w}}{\partial y}
$$

where $\lambda$ is heat conductivity coefficient of the used wall material.

Partial differential equations (16) and (17) with relevant initial and border conditions completely describe non-stationary one-dimensional heat flow [17].

As we mentioned above we have expressed dependent variables by their values and increments and by substitutions and subtractions we have got partial differential equations system of heat transfer dynamics through the wall:

$$
\begin{aligned}
-\frac{\partial \Delta \Phi}{\partial y} & =c \cdot \rho \cdot \frac{\partial \Delta \theta_{w}}{\partial t} \\
\Delta \Phi & =-\lambda \frac{\partial \Delta \theta_{w}}{\partial y}
\end{aligned}
$$

To simplify computation, we have expressed each of dependences in non-dimensional form and then we can express partial differential equations (18) and (19) in a form:

$$
\begin{gathered}
\frac{\partial x_{\Phi}}{\partial y}+c \cdot \rho \cdot \frac{d_{w}}{\lambda} \frac{\partial x_{\theta w}}{\partial t}=0 \\
x_{\Phi}+d_{w} \frac{\partial x_{\theta w}}{\partial y}=0
\end{gathered}
$$

Equations (16), (17) or (20), (21) still need to be supplemented by equations of heat transfer on both sides of the wall surfaces. In dimensionless form for indoor surface area it is valid:

$$
x_{\Phi 1}=x_{\Phi 1}^{*}-\kappa_{1} \cdot x_{\theta w 1}=\left(x_{\theta a 2}-x_{\theta w 1}\right) \cdot h_{1}-\kappa_{1} \cdot x_{\theta w 1}
$$

where $x_{\Phi 1}^{*}$ includes also external effects on the heat flow transfer into the wall (temperature changes or heat transfer coefficient changes, etc.), $\kappa_{1}=\frac{h_{1} \cdot d_{w}}{\lambda}$ and $h_{1}$ is heat transfer coefficient between air and wall surface $\left[\mathrm{W} \cdot \mathrm{m}^{-2} \cdot \mathrm{K}^{-1}\right]$. 
Similarly, for outdoor surface area it is valid:

$$
x_{\Phi 2}=x_{\Phi 2}^{*}+\kappa_{2} \cdot x_{\theta w 2}=\left(x_{\theta w 2}-x_{\theta o}\right) \cdot h_{2}+\kappa_{2} \cdot x_{\theta w 2}
$$

where $x_{\Phi 2}^{*}$ includes external conditions of the heat flow transfer from the wall, $\kappa_{2}=\frac{h_{2} \cdot d_{w}}{\lambda}$ and $h_{2}$ is heat transfer coefficient between wall surface and air $\left[\mathrm{W} \cdot \mathrm{m}^{-2} \cdot \mathrm{K}^{-1}\right]$.

\subsection{Dynamic model of heat transfer through the wall}

By the Laplace transform of partial differential equations (20) and (21) and by the other mathematical operations it has been possible to get a system of equations, which describes dependence of non-dimensional variables for heat flows $\Phi_{1}, \Phi_{2}$ and temperatures $\theta_{w 1}, \theta_{w 2}$.

Laplace transform image of partial differential equations system is:

$$
\begin{gathered}
\overline{\bar{X}}_{\Phi}=\frac{q}{q^{2}-p} \bar{X}_{\Phi 1}-\frac{p}{q^{2}-p} \bar{X}_{\theta w 1} \\
\overline{\bar{X}}_{\theta w}=-\frac{1}{q^{2}-p} \bar{X}_{\Phi 1}+\frac{q}{q^{2}-p} \bar{X}_{\theta w 1}
\end{gathered}
$$

Using inverse Laplace transform we have got following equations:

$$
\begin{gathered}
\bar{X}_{\Phi}=\cosh \sqrt{p} \cdot \bar{X}_{\Phi 1}-\sqrt{p} \cdot \sinh \sqrt{p} \cdot \bar{X}_{Q w 1} \\
\bar{X}_{Q w}=-\frac{\sinh \sqrt{p}}{\sqrt{p}} \cdot \bar{X}_{\Phi 1}+\cosh \sqrt{p} \cdot \bar{X}_{Q w 1}
\end{gathered}
$$

Let denote $\bar{X}_{\Phi}=\bar{X}_{\Phi 2}$ and $\bar{X}_{\theta_{w}}=\bar{X}_{\theta_{w 2}}$. And simultaneously because that the unknowns variables are the heat flow $\Phi_{2}$ taken away from the refrigerated wall surface and temperature $\theta_{w 1}$ of the heated wall surface, we express $\bar{X}_{\Phi 2}$ and $\bar{X}_{\theta w 1}[2]$ :

$$
\begin{gathered}
\bar{X}_{\Phi 2}=\frac{1}{\cosh \sqrt{p}} \bar{X}_{\Phi 1}-\sqrt{p} \cdot \operatorname{tgh} \sqrt{p} \cdot \bar{X}_{\theta w 2} \\
\bar{X}_{\theta w 1}=-\frac{\operatorname{tgh} \sqrt{p}}{\sqrt{p}} \bar{X}_{\Phi 1}+\frac{1}{\cosh \sqrt{p}} \bar{X}_{\theta w 2}
\end{gathered}
$$

with transfer functions:

$$
\begin{gathered}
G_{1}(p)=\frac{1}{\cosh \sqrt{(p)}} \\
G_{2}(p)=\sqrt{(p)} \cdot \operatorname{tgh} \sqrt{(p)} \\
G_{3}(p)=\frac{\operatorname{tgh} \sqrt{p}}{\sqrt{(p)}}
\end{gathered}
$$

Next problem is to find function which corresponds to (26) and (27) using inverse Laplace transform. Due to the fact, that transfer functions (28)-
(30) are not defined as images, we have to use Taylor series and substitution $p=T_{s} \cdot s$. Thus we get transfer functions:

$$
\begin{gathered}
G_{1}(p)=\frac{24}{24+12 T_{s} s+T_{s} s^{2}} \\
G_{2}(p)=\frac{4\left(6 T_{s} s+T_{s} s^{2}\right)}{24+12 T_{s} s+T_{s} s^{2}} \\
G_{3}(p)=\frac{120+20 T_{s} s+T_{s} s^{2}}{5\left(24+12 T_{s} s+T_{s} s^{2}\right)}
\end{gathered}
$$

where $T_{s}=\frac{d_{w}^{2} \cdot \rho \cdot c}{\lambda}$ is constant which is depended on the wall properties.

Based on the terms (28) till (35) for non-dimensional variables the block diagram of dynamic model of heat transfer through the wall was designed (Fig. 4).

Input variables into model are non-dimensional variables: temperature of the heated air in the room $X_{\theta a 2}$ and outdoor temperature $X_{\theta_{o}}$ Output variables from model are non-dimensional variables of the wall temperatures $X_{\theta w 1}$ and $X_{\theta w 2}$ [18-20].

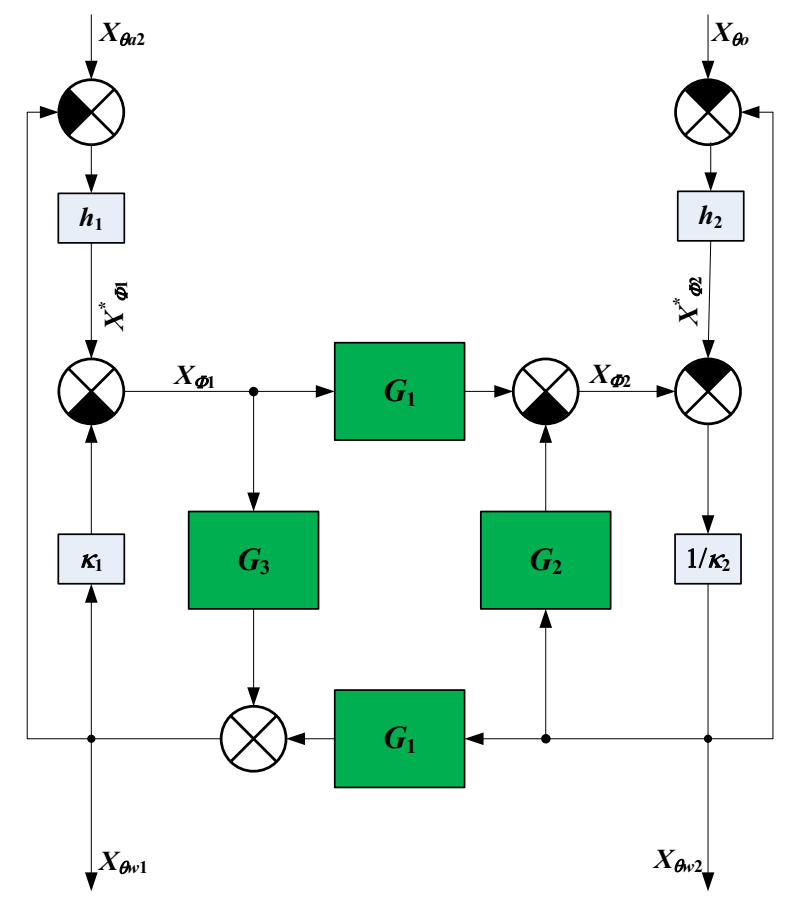

Fig. 4. Block diagram of dynamic model of heat transfer through the wall.

\section{Conclusion}

Dynamic model of heat transfer from the heating body to the heated room consists of two relative separated models: model of the heating body and model of heat transfer through the wall to the outdoor environment. Interconnection of these two models is presented in Fig. 5.

The designed dynamic model will be the basis for creating the simulation model of the heating system in Matlab/Simulink environment [21-25]. 


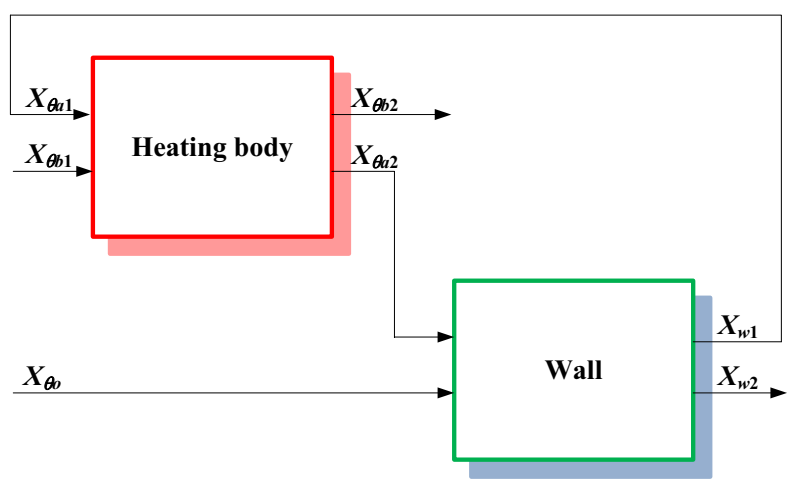

Fig. 5. Block diagram of dynamic model of heat transfer from the heating body to the heated room.

\section{Acknowledgment}

This work was supported by the Slovak Research and Development Agency under the contract No. APVV-150602 and also by the Project of the Structural Funds of the EU, ITMS code: 26220220030.

\section{References}

1. H. Charvatova, D. Janacova, R. Drga, O. Liska, V. Vasek, M. Zalesak, Computer modeling of heat balance in counterflow tube heat exchanger. International Journal of Mechanics, 7 (4), pp. 385 392 (2013)

2. J. Čermák, V. Peterka, J. Závorka, Dynamika regulovaných soustav $v$ tepelné energetice a chemii, 584 p. (1968)

3. I. Čorný, L. Straka, J. Mihalčová, Konvekčné modely a ich aplikácia $\mathrm{v}$ simulačných programoch $\mathrm{v}$ technike prostredia. Strojárstvo extra, 12 (5), pp. 6/1-4 (2009)

4. F. Hruška, Model konvekčního topného tělesa, in MATLAB 2002, Praha, pp. 202-206 (2002)

5. F. Hruška, J. Pitel', Analytický model prostředí interiéru jako regulované soustavy, in Workshop "Human Factor and Environmentalist", ViennaKošice, pp. 41-42 (2002)

6. D. Janacova, H. Charvatova, K. Kolomaznik, M. Fialka, P. Mokrejs, V. Vasek, Interactive software application for calculation of nonstationary heat conduction in a cylindrical body. Computer Applications in Engineering Education, 21 (1), pp. 89-94 (2013)

7. V. Vasek, K. Kolomaznik, D. Janacova, Tannery wastes processing distributed control system, in International Conf. on CAD/CAM, Robotics and Factories of the Future, Durban, pp. 894-900 (2001)

8. M. Rimár, I. Čorný, M. Fedák, Analýza a syntéza riadenia tepelných sústav, 190 p. (2013)

9. V. Vasek, P. Dostalek, J. Dolinay, D. Janacova, K. Kolomaznik, Microcontrollers and modern control methods, in WSEAS International Conference on Computer Engineering and Applications, Mexico, pp. 195-198 (2008)
10. A. Hošovský, J. Pitel', Základy automatického riadenia, 97 p. (2013)

11. J. Pitel, J. Borzikova, Model of the heating body for heating process control using, in MMTT 20, Jaroslavl, pp. 78-80 (2007)

12. J. Pitel', T. Saloky, Simulačný model teplovodného vykurovacieho telesa. Acta Metallurgica Slovaca, 13, pp. 301-306 (2007).

13. H. Charvatova, D. Janacova, K. Kolomaznik, Study of non-stationary heat conduction in a plane plate for symmetric and asymmetric problem. WSEAS Transactions on Heat and Mass Transfer, 6 (1), pp. 51-60 (2011)

14. J. Pitel, Model of the heated space for heating process control using, in MMTT 19, Voronez, pp. 141-143 (2006)

15. I. Corny, M. Fedak, Equation model of thermal comfort parameters, in Energy transformation in industry, High Tatras, pp. 25-27 (2013)

16. I. Corny, Mathematical model of thermal parameters, in Operation and diagnostics of machines and production systems operational states, Brno, pp. 15-18 (2008)

17. J. Pitel', Matematický model prestupu tepla stenou pre simuláciu riadenia procesu vykurovania, Acta Metallurgica Slovaca, 13, pp. 296-300 (2007).

18. H. Charvatova, M. Zalesak, S. Sehnalek, D. Janacova, V. Vasek, R. Drga, Computer simulation of parameterized module for testing of thermal stability in the room. International Journal of Mathematics and Computers in Simulation, 9, pp. 53-59 (2015)

19. J. Mizakova, S. Hrehova, A. Hosovsky, Simulation model of heat transfer through the wall, in International conference on Applied Mathematics and Computational Methods, Venice, pp. 195-200 (2013)

20. J. Mizakova, J. Pitel, S. Hrehova, Some simulation results of heat transfer through the wall. International Journal of Mathematical Models and Methods in Applied Sciences. 8, pp.1-8, (2014)

21. M. Balara, M. Tóthová, Simulačný model riadenia vykurovacieho systému s kaskádnou regulačnou štruktúrou, in ARTEP 2015, Stará Lesná, pp. 32-1 7 (2015).

22. I. Corny, Application of simulation control in building energy system. Acta Technica Corviniensis, 2 (3), pp. 25-31 (2009)

23. M. Tóthová, M. Balara, Simulácia riadenia vykurovacieho systému $\mathrm{S}$ kaskádnou regulačnou štruktúrou (1). iDB Journal, 5 (2), pp. 44-45 (2015)

24. M. Fedak, I. Corny, Building energy performance simulation and its evolution, in $M M S$ 2014, Stary Smokovec, pp. 42-46 (2014)

25. M. Tothova, M. Balara, J. Dubjak, Simulation model of cascade control of the heating system. International Journal of Engineering Research in Africa, 18, pp. 20-27 (2015) 